\title{
Urgences
}

\section{... Ils sont tous là}

\section{Vianney Gallant}

Numéro 19, janvier 1988

Le tour du texte

URI : https://id.erudit.org/iderudit/025447ar

DOI : https://doi.org/10.7202/025447ar

Aller au sommaire du numéro

Éditeur(s)

Urgences

ISSN

0226-9554 (imprimé)

1927-3924 (numérique)

Découvrir la revue

Citer ce document

Gallant, V. (1988). ... Ils sont tous là. Urgences, (19), 75-77.

https://doi.org/10.7202/025447ar

Ce document est protégé par la loi sur le droit d'auteur. L'utilisation des services d'Érudit (y compris la reproduction) est assujettie à sa politique d'utilisation que vous pouvez consulter en ligne.

https://apropos.erudit.org/fr/usagers/politique-dutilisation/
Cet article est diffusé et préservé par Érudit.

Érudit est un consortium interuniversitaire sans but lucratif composé de l’Université de Montréal, l'Université Laval et l'Université du Québec à Montréal. Il a pour mission la promotion et la valorisation de la recherche. https://www.erudit.org/fr/ 


\section{Vianney Gallant \\ ... ILS SONT TOUS LÀ}

Le roman est né non pas de l'esprit théorique, mais de l'esprit de I'humour. |... J' Jai trop peur des professeurs pour qui lart n'est qu'un dérivé de courants philosophiques et theoriques.

Milan Kundera

... Ils sont tous là à manxiéter, à m'horrifier, avec leur glasnost incarcérable. Le nuage tchernobiblique m'arcane le dogme scientocratique. Allez comprendre ce qui me prend chaque jour à la même heure de recommencer à respirer, tellement c'est un travail, prana, pneuma et chambre des naissances. Tout cela me donne la litost et me délivre du vivre et de l'oubli, je me noie dans le spleen, à cause de la langue française. C'est épiphanique, dédalusien.

Mirek, cette vieille andouille, m'a encore télépathié via la bibliothèque municipale. Comme à un anonyme. Il me confond avec Christianssen alors que je confisque la clinique. C'est à rendre malade. II me dit de ne pas y aller trop fort avec le lithium car la vie est ailleurs et l'agressivité créatrice. Y parait que c'est bipolaire, cyclique, et que je n'ai rien à y voir comme individu, pas plus que le dictionnaire.

- Toujours ce castrat monsieur Mirek (car je l'épèle par son prénom de Dieu pour cause d'omniscience)!

À l'autre bout il se défile entre les lignes.

- C'est une plaisanterie ou quoi?

II faudrait évidemment tout souligner. Mais, en fait, je n’ai pas non plus assez d'espace pour les guillemets. Et puis, je suis loin d'ètre certain d'avoir le droit de cité en fiction. D'ailleurs, il y a beaucoup trop de noms qui ont déjà porté un mot comme des personnes (et c'est la République, res publica, la chose étymologiste connotée par le plus vieux métier du monde).

- Non pas du tout que je lui dis, vous avez deviné (je le vouvoie malgré l'utilisation prénommée de sa première personne). j achète la clinique.

Il prend son ton ordinaire. 
- Ne faites pas du Jaromil via Lermontov et cie... ça ne vous va pas etc..., car on ne peut pas tout dire en littérature.

Le vieil enfantôme pour la description exécute une pause. Je suis éberlué. II n'arrête jamais de parler d'habitude.

\section{- Et votre roman?}

Je ne suis pas habitué à ce qu'on me pose. Alors c'est le cliché. La guerre aux types du genre. Voire leur mort. La réponse ne vient pas. On dirait un autre. Ça devient dingue. L'autre est un je depuis un satané début des temps modernes. Ça implique.

- L'art du...

— Non! Non! Non! Et non! Le tien!!! L'holographie...

Le millénaire eut un râle autobiobibliographique. Ça peut avoir l'air compliqué mais ça se saisit d'un trait qui a du génie. II en avait l'énumération et ça gonflait Québécois.

- Je me réoriente que je lui réponds, j'achète la clinique et un point c'est tout comme la partie. Je suis désespéré d'être client. J'ai mis le protecteur de la consommation à sa trousse (je vais pouvoir distribuer les honneurs de la maladie à qui je veux, avec les lettres de noblesse héréditaires et les subventions soulignées).

- Christianssen?...

$-? .$.

- Ca va si mal que ça à Copenhague?

- Y a quelque chose de pourri car y a des limites à se laisser prendre dans la soupière pour vendre la mèche. Ça m'amibe à cause de la voix d'extinction. Autrement, c'est la pava ou pire, la fièvre bovarine.

Mais pensez donc que je suis embarrassé. Je suis pris dans ma conscience du rouage. Vécrire ou ne pas vécrire. D'une part y a l'inspiration et d'autre part le travail du signifiant. Je pratique l'art pour l'art du compromis. Alors j'inspire en travaillant. C'est peut-être l'alternative au singulier à cause du sens français (mais pour relâcher le souffle avant l'étourdissement y a le style comme pastiche angliciste). 
II insiste. J'inspire. II vient me voir. Je travaille. II renifle partout sans détour. II s'asseoit. J'organise mon répondeur automatique pour l'imperméable du sensible.

- Ça ne se fait pas de vécrire un dialogue entre un auteur et le personnage d'un autre... C'est du plagiat, de la surenchère spéculaire...

Cette fois, il avait pris un air ordinaire pour mieux parler de lui, seul à seul avec son monologue à oreilles. L'air ordinaire, $y$ a rien de meilleur à fredonner, c'est stéréo et le type n’a pas à se forcer pour se comprendre. Les oreilles aussi, c'est super, à condition qu'elles ne soient pas toutes du même côté du mur. Autrement c'est le poison... Pas pour rien qu'on dit prêter une oreille attentive... la gauche oui, car y faut protéger sa droite en quelque sorte pour qu'il l'entende. Faut savoir bander les oreilles qui n'ont qu'un côté de la médaille. Je les connais les écrivains. Ce sont des frappés du vrai petit mensonge esthétique. Et nécrophiles à part de ça. Des rats qui dégoûtent à la bibliothèque. Des sonnés même, à cause de l'argent liquide, la pension, le curriculum et l'agenda.

- Et le libre-échange que je lui réponds, je ne peux quand même pas puiser dans mon être profond terrorisé par les théoriciens du Nouveau Roman. Alors je procède, je fabrique, je broute l'héritage des grands suicidés du sens.

- Même ce qu'on se dit s'énonce mal comme conversation. Trop didactique cette partie dialogique qu'il me dit ou quelque chose comme ça.

- Alors sortez vos canons quion se tire un peu de dogme et de théorie, de must et d'allégorie...

- Encore cette crise d’authenticité quiil me dit. Et qu'il me perce à jour.

- Pas pire que l'expressophobie, non? que je lui crie, exacerbé à moins que ce ne soit exaspéré (non je ne chercherai pas dans le dictionnaire).

On aurait pu se chicaner longtemps comme des générations littéraires. Mais lui, c'est un sage. Il se souvient des agélastes qui avaient le rire coagulé quelque part dans le seizième arrondissement temporel... 